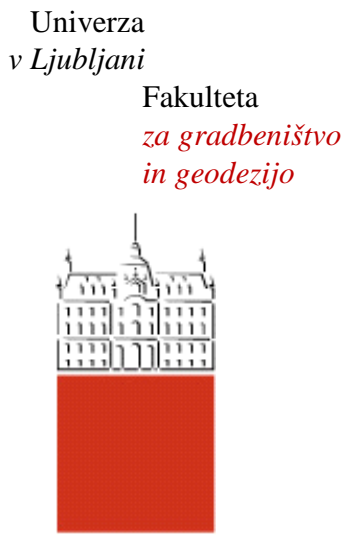

Jamova 2

1000 Ljubljana, Slovenija http://www3.fgg.uni-lj.si/

DRUGG - Digitalni repozitorij UL FGG http://drugg.fgg.uni-lj.si/

Ta članek je avtorjeva zadnja recenzirana različica, kot je bila sprejeta po opravljeni recenziji.

Prosimo, da se pri navajanju sklicujete na bibliografske podatke, kot je navedeno:

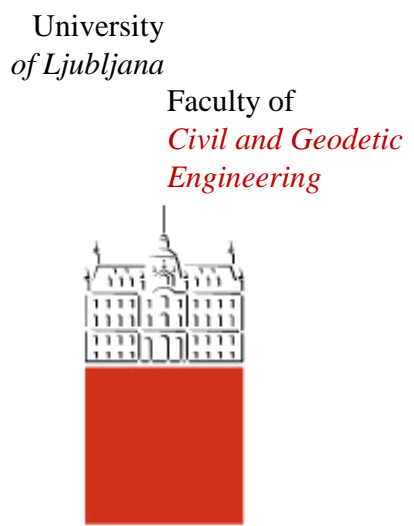

Jamova 2

SI - 1000 Ljubljana, Slovenia http://www3.fgg.uni-lj.si/en/

DRUGG - The Digital Repository http://drugg.fgg.uni-lj.si/

This version of the article is author's manuscript as accepted for publishing after the review process.

When citing, please refer to the publisher's bibliographic information as follows: 


\title{
Modelling soil behaviour in uniaxial strain conditions by neural networks
}

\author{
Goran TURK*, Janko LOGAR, Bojan MAJES \\ University of Ljubljana, Faculty of Civil and Geodetic Engineering, \\ Jamova 2, SI-1001 Ljubljana, Slovenia
}

\begin{abstract}
The feed-forward neural network was used to simulate the behaviour of soil samples in uniaxial strain conditions, i.e. to predict the oedometer test results only on the basis of the basic soil properties. Artificial neural network was trained using the database of 217 samples of different cohesive soils from various locations in Slovenia. Good agreement between neural network predictions and laboratory test results was observed for the test samples. This study confirms the link between basic soil properties and stress-strain soil behaviour and demonstrates that artificial neural network successfully predicts soil stiffness in uniaxial strain conditions. The comparison between the neural network prediction and empirical formulae shows that the neural network gives more accurate as well as more general solution of the problem.
\end{abstract}

Keywords: oedometer test, artificial neural network, soil characteristics

\section{Introduction}

Neural networks have been extensively used in structural mechanics [1], predominantly in structural optimization [2], damage detection and identification and finite element mesh generation. Reports on using artificial neural networks in the prediction of material behaviour are not so numerous. One of the early works in this area was reported by Ghaboussi et al [3]. Biaxial monotonic and uniaxial cyclic behaviour of concrete was modelled using feed-forward neural network based on a relatively large set of samples of essentially the same material. Stress-strain relations of sands and the shearing behaviour of residual soils in triaxial stress-strain conditions have been modelled by artificial neural networks $[4,5]$.

${ }^{*}$ Corresponding author (fax: +386 1 4768629, email: gturk@fgg.uni-lj.si) 
It is difficult to get several samples of soil with the same behaviour, even when the samples are taken from the same soil layer. Slight changes of water content, liquid limit, plasticity index, grain size distribution and different overburden pressure for samples taken from different depths as well as other factors cause different behaviour of samples from apparently the same material.

This is the reason for extensive testing of soil samples in each geotechnical engineering project. A lot of experimental data are available which had been used in certain projects and were practically forgotten later on. Could these old files be used as active knowledge also in the present and future geotechnical projects? The main goal of our work was to answer this question. We were encouraged by the fact that several authors have published some simple correlation formulae between the basic soil properties, such as liquid limit $w_{L}$, plastic limit $w_{p}$, plasticity index $I_{P}$, and mechanical soil properties, such as the angle of internal friction, compression index $\left(C_{c}\right.$ or $\left.\lambda\right)$ and expansion index $\left(C_{e}\right.$ or $\left.\kappa\right)$. A list of empirical formulae presented by Azzouz et al. [6] is shown in Table 1.

In the first step, described in an earlier paper [7], we collected 46 oedometer test results on samples from typical Ljubljana marshland soil. Even though all the samples belong to the same soil layer, large differences in initial water content, liquid limit and plastic limit were found (Figure 1a). Consequently the stress-strain behaviour of these samples was also considerably different (Figure 1b).

We decided to train the feed-forward neural network on the behaviour of random selection of 40 test results. The test results of the other 6 samples were used for testing the neural network predictions. Due to differences in the basic soil properties, the training data included, in addition to the stress- strain curve, also initial water content, liquid and plastic limit and overburden pressure. Neural networks with different number of hidden layers and different number of hidden neurones were tested. A good agreement between the neural network prediction and the measured stress-strain curves was obtained using a neural network with one hidden layer.

This result encouraged us to use the trained neural network as a material model in a FEM code [8]. Since this task means the reproduction of trained data and not the prediction of stress-strain curves which were unknown to the neural network, we expected and obtained good results (Figure 2).

The present paper will discuss the next step in our research. The database of oedometer test results was extended by adding tests performed on samples from many different sites 
all around the geologically heterogeneous Slovenian territory.

Additionally, the unloading parts of the oedometer curves were introduced wherever they were available.

\section{Artificial neural network}

The geometry of a multi-layer feed-forward neural network is shown in Figure 3. Each connection between two units is represented by its weight $w_{i j}^{k}$, where index $i$ corresponds to the unit number of $(k-1)^{t h}$ layer, while index $j$ corresponds to the unit number of $k^{\text {th }}$ layer. The value of a unit is multiplied by the corresponding weight and added to the value of signal in the unit of the next layer

$$
y_{i}^{k}=\mathrm{f}\left(y_{i}^{\prime k}\right)=\mathrm{f}\left(\sum_{j=1}^{n_{k-1}} w_{i j}^{k} y_{i}^{k-1}\right)
$$

The activation function $\mathrm{f}($.$) used in our application is a sigmoid function 1 /\left(1+e^{-y}\right)$. The

results of the neural network depend on the values of the weights $w_{i j}^{k}$ which have to be determined by the learning (training) procedure.

A set of known input and output values is termed as input-output pair. All inputoutput pairs are usually divided into two sets. The first is termed as learning or training set which is used to determine the connection weights $w_{i j}^{k}$. The second, named testing set is used to test the performance of the taught neural network. The error back-propagation (or "generalized delta rule", as it was termed by its authors Rummelhart and McClelland [9]) employed in the training procedure is a gradient method in which the weights are changed for a chosen step size in the direction of the maximum descent for each inputoutput pair. The procedure is repeated for each input-output pair until the error is smaller than prescribed for all input-output pairs.

The details concerning artificial neural networks may be found in many textbooks (see e.g. Reed and Marks II [10]).

\section{Database}

Oedometer test is a standard soil deformability test in uniaxial strain conditions. It is normally performed in a stress loop. Only a smaller part of deformations observed during the loading is recovered during the unloading. The typical oedometer curve is presented in semi-logarithmic scale in Figure 4. The slope of the straight portion of the loading 
curve is a soil compression index $C_{c}$ and the slope of the unloading curve is soil expansion index $C_{e}$. Void ratio increment $\Delta e$ can be expressed in terms of compression index $C_{c}$ or expansion index $C_{e}$ by the following equations:

$$
\begin{array}{ll}
\Delta e=C_{c} \log \frac{\sigma_{0}-\Delta \sigma}{\sigma_{0}} & \text { normally consolidated } \\
\Delta e=C_{e} \log \frac{\sigma_{0}-\Delta \sigma}{\sigma_{0}} & \text { over - consolidated }
\end{array}
$$

These indices were used for the comparison of neural network predictions with the measured stress-strain curves.

We collected the oedometer test results from 241 samples. 217 tests were used for training and 24 for the testing of neural network predictions. For all of these samples initial water content and Atterberg limits were known. Figure 5 presents the plasticity chart and the corresponding oedometer curves of all samples included in the database. Table 2 shows the extreme and average values of relevant soil parameters.

Since some of the samples were taken from overconsolidated soils, the overburden pressure could not be used any more as a stress history parameter and was substituted by the overconsolidation pressure which had to be determined for each sample. The following input parameters were used:

- $w_{0}$ natural water content,

- $w_{L}$ liquid limit,

- $I_{P}$ plasticity index,

- $\sigma_{P}$ overconsolidation pressure,

- $\sigma_{i-1}$ previous vertical stress,

- $e_{i-1}$ previous vertical strain in terms of void ratio,

- $\Delta \sigma_{i}$ stress increment.

The only output parameter was

- $\Delta e_{i}$ strain increment in terms of void ratio.

\section{Neural network prediction of the oedometer loading curve}

Different neural networks with 15 to 100 neurones in one hidden layer and 10 to 50 neurones in each of two hidden layers were trained and tested later on. The best predictions were obtained with 45 neurones in one hidden layer. Generally the neural network prediction based on training with the extended database was slightly less accurate than the 
predictions in the previous case, where only one soil type was taken into consideration. Some of the results of neural network predictions of test samples behaviour compared with the measured results are shown in next figures. Figure 6 presents the results on samples from test set with good agreement between the predicted and the measured values.

Some predictions exhibited interesting deviations from the expected results. Test sample No. 2 was tested up to unusually high vertical stress of $1700 \mathrm{kPa}$ (Figure 7). There was also a large stress increase from 400 to $1100 \mathrm{kPa}$. Within the training set all stress increments were much lower. For this reason the neural network could not predict the correct strain increment for this case, as shown in Figure 7 (case NN45). When this stress increment was subdivided into smaller stress increments, the predicted curve got the correct shape, however the exact values were not obtained.

The test sample No. 22 exhibited swelling during the first loading step (Figure 8). This means that the laboratory test was not carried out strictly according to standards. Moreover the liquid and plastic limits of the sample were outside the range of these parameters within the training set. Nevertheless the neural network prediction agreed well with the measurements. Only the swelling behaviour observed in the first load step that had not been trained was not reproduced.

The measured stress-strain points of the test sample No. 24 show that an unwanted loading occurred at the loading step of $24 \mathrm{kPa}$ (Figure 9). Neural network prediction follows the trained behaviour and at the end reaches the measured values of strains.

Generally it can be observed that some test results were predicted very well and others with less accuracy. The main reason is attributed to the fact that 217 samples included in the training set are still a small number compared to numerous combinations of the basic soil parameters, stress-strain behaviour and laboratory conditions (stress increments) that can be of our interest. We strongly believe that more reliable predictions can be obtained with further enlargement of the database.

\section{The neural network prediction of unloading curve}

So far only the loading curve of the oedometer test results were studied. As a next step we wanted to extend the research to the unloading part of the oedometer curve. We used the same database. By simply repeating the procedure used in the prediction of the loading curve extremely disappointing results were obtained. The predicted oedometer curves had got not only wrong values but even wrong shape. From Figure 10 which shows the results on test sample No. 4 it can be observed that even the loading curve which was 
previously determined with sufficient accuracy obtained a wrong shape. It was obvious that the data on the unloading had a negative effect on the training of the loading part of the oedometer curve. The solution to this problem was to add a switch for loading and unloading as an additional input parameter. After that the predicted oedometer curves got the right shape. The loading curve was still not predicted with the same accuracy as in the case where only the loading curve was trained.

As the final step we tried to change the overconsolidation pressure after the completion of the loading cycle. This is physically correct since the overconsolidation pressure is defined as the highest pressure at which the sample has ever been consolidated. Such a change in the training data set contributed to the improved prediction of the loading as well as the unloading part of the oedometer curves. For certain tasks, e.g. prediction of plastic (unrecoverable) deformations, where only the difference between the loading and the unloading curve is important, the neural network prediction is acceptable, since the unloading deformations are very small compared to loading deformations. If, however, an accurate prediction of expansion index $C_{e}$ is needed, the neural network results are at the present stage not reliable enough. Figure 11 presents the results on selected test samples. The results of two different training procedures are compared. Dashed line presents the results obtained with eight input parameters (loading - unloading switch was added to the original seven input parameters), whereas solid line presents the results with eight input parameters and changed overconsolidation pressure.

\section{Two cycles of loading and unloading}

By changing the overconsolidation pressure after the last loading step we formed the basis for the successful prediction of a new loading cycle. Since there was no such test in our database, we could only make a qualitative judgement. Figure 12 shows the neural network prediction of the soil behaviour during two loading - unloading cycles. We can see that neural network can reproduce the general rules of elastoplastic soil behaviour in uniaxial strain conditions.

\section{Discussion}

Five different training procedures were used in this study:

A. loading curve alone with the original seven input parameters and one output parameter, 
B. unloading curve alone with the original seven input parameters and one output parameter,

C. simultaneous training of the loading and unloading curve with the original seven input parameters and one output parameter,

D. simultaneous training of the loading and unloading curve with a switch for loading and unloading as the eighth input parameter,

E. simultaneous training of the loading and unloading curve with a switch for loading and unloading as the eighth input parameter and changed overconsolidation pressure after completed loading.

Table 3 shows the error analysis depending on the training procedure. Four parameters, for which the maximum, the mean and the median are shown in Table 3, were used as a measure of error:

- normalised error in individual stress-strain point prediction:

$$
\Delta e_{1}=\left|\frac{e_{\mathrm{NN}}-e_{\text {test }}}{e_{\text {test }}}\right|
$$

where $e_{\text {test }}$ and $e_{\mathrm{NN}}$ are the values of void ratio in the testing data set and its neural network approximation, respectively.

- the average error of individual stress-strain curve prediction:

$$
\Delta e_{2}=\frac{1}{N} \sum_{i=1}^{N} \Delta e_{1 i},
$$

where $N$ is the number of stress-strain points of oedometer curve.

- normalised error in the prediction of the compression index:

$$
\Delta C_{c}=\left|\frac{C_{c \mathrm{NN}}-C_{c \text { test }}}{C_{c \text { test }}}\right|
$$

where $C_{c \text { test }}$ and $C_{c \text { NN }}$ are the values of the compression index determined from the testing data set and its neural network estimate, respectively.

- error in the prediction of expansion index $\Delta C_{e}$. The actual values of expansion index $C_{e}$ are relatively low. Therefore the normalised errors with respect to the value of $C_{e}$ are at times extremely high. As we tried to compare the prediction of loading and unloading part of oedometer curves, the errors of index $C_{e}$ prediction were normalised with respect to the corresponding value of $C_{c}$ :

$$
\Delta C_{e}=\left|\frac{C_{e \mathrm{NN}}-C_{e \text { test }}}{C_{c \text { test }}}\right|
$$


where $C_{e \text { test }}$ and $C_{e N N}$ are the values of the expansion index determined from the testing data set and its neural network estimate, respectively.

Table 3 shows that training procedures A, D and E give similar results, if only the loading part of the oedometer curve is considered. The predictions of individual points are slightly less accurate when the loading and unloading curves are trained simultaneously (cases D and E), whereas the prediction of the compression index $C_{c}$ is slightly improved. The overall prediction is the worst in case C, but surprisingly gives the lowest errors for expansion index $C_{e}$.

During the training process it was observed that artificial neural network could not learn some of the training data up to the required accuracy of $2 \%$. After a careful analysis of the training data set we found out that there were some groups of test samples in our database that had very similar Atterberg limits and water content but exhibited different behaviour in the oedometer test. An example of such a group of tests is presented in Figure 13. Three samples (No. 26, 29 and 30) had been taken from the same soil layer. Laboratory results showed that the differences in the basic soil parameters were within $2 \%$. Two oedometer curves coincided well, the third, however, (No. 26) was slightly more deformable. Incidentally, sample No. 26 was included in the training set and the other two samples in the test data set. As one would expect, the neural network prediction followed the trained behaviour. Such cases show the need for a much larger database.

We studied large differences in laboratory observations and neural network predictions in more detail. No evident relationship between the errors in approximated indices, such as $C_{c}$ and $C_{e}$, and the basic soil parameters could be found. Since all the available data on the tested soil samples were included in the training process, we can only state a hypothesis at this stage that some other soil parameter governs the unloading behaviour of soil samples in uniaxial strain conditions. This parameter can be either the shape of individual grains or soil texture or shrinkage limit. These parameters are not routinely investigated and were not known for the samples from our database. If such a hypothesis proved to be correct, this would be of great importance for understanding the soil behaviour. Other parameters such as grain size distribution and mineralogical composition are indirectly included in the study via Atterberg limits.

Table 4 presents the comparison between the neural network prediction of compression index $C_{c, A N N}$ and empirical formulae $C_{c, 1}$ to $C_{c, 6}$ given in Table 1 . It can be seen that the neural network prediction gives the highest correlation coefficient and the lowest error for 
the testing data set. Also, it has to be noted, that the user of empirical formulae has to make a correct choice of the most appropriate one for the type of soil under consideration, whereas the neural network estimate includes all types of soils which were included in the training database.

\section{Conclusions}

On the basis of the presented research we can draw the following conclusions:

- Artificial neural network can serve as a simple material model, since it can reproduce the material behaviour without the necessity of understanding the background for such behaviour.

- The loading curve of the oedometer test results obtained from very different soil samples can be not only reproduced but also predicted by using trained feed forward neural networks. The prediction is based only on the basic soil parameters.

- At this stage we can only make the hypothesis that some other factors that were not included in the training process (e.g. the shape of soil particles, soil texture, shrinkage limit) play a major role in the unloading characteristics of soils.

- A much larger database would lead to better predictions. A special care should be taken in the selection of the laboratory data. Not all tests are performed strictly according to standards.

- Collecting all tests from past projects is of great importance, since such data can be used to establish empirical correlation between soil parameters. The use of artificial neural networks is certainly an improvement with respect to known empirical relationships between many soil parameters.

\section{References}

1. Topping BHV, Bahreininejad A. Neural Computing for Structural Mechanics. Edinburgh: Saxe-Coburg Publications, 1997.

2. Berke L, Hajela P. Application of Artificial Neural Nets in Structural Mechanics. Journal of Structural Optimization 1992; 90-98.

3. Ghaboussi J, Garrett jr JH, Wu X. Knowledge-Based Modelling of Material Behaviour with Neural Networks. Journal of Engineering Mechanics ASCE 1990; 117(1), 132153. 
4. Ellis GW, Yao C, Zhao R, Penumadu D. Stress-strain modelling of sands using artificial neural networks. Journal of Geotechnical Engineering Division ASCE 1995; 121 (5), 429-435.

5. Zhu J-H, Zaman MM, Anderson SA. Modelling of Shearing Behaviour of a Residual Soil with Recurrent Neural Network. International Journal for Numerical and analytical Methods in Geomechanics 1998; 22, 671-687.

6. Azzouz, AS, Krizek, RJ, Corotis, RB. Regression Analysis of Soil Compressibility. Soils and Foundations 1976; 16 (2), 19-29.

7. Logar J, Turk G. Modelling of the oedometer test by neural networks. IABSE Colloquium Report: Knowledge Support Systems in Civil Engineering, Bergamo 1995; $273-281$.

8. Logar J, Turk G. Neural networks as constitutive model for soil. ZAMM 1997; 77, Suplement I, 187-188.

9. Rumelhart DE, McClelland JL. Parallel Distributed Processing, Volume 1: Foundations. Cambridge (MA): The MIT Press, 1986.

10. Reed, RD, Marks II, RJ. Neural Smithing. Cambridge (MA): The MIT Press, 1999. 


\section{Figures}

Figure 1: a) Plasticity chart of 46 Ljubljana marshland soil samples

b) Oedometer curves of 46 oedometer tests of Ljubljana marshland soil

Figure 2: Comparison between settlement prediction of neural network and Cap model

Figure 3: Multi-layer feed-forward neural network

Figure 4: Typical oedometer curve with definitions of $C_{c}$ and $C_{e}$

Figure 5: a) Plasticity chart of 241 soil samples from different parts of Slovenia

b) Corresponding oedometer curves

Figure 6: Some successfully approximated oedometer curves

Figure 7: Oedometer curve for exceptionally high stresses

Figure 8: Swelling behaviour has not been accounted for

Figure 9: Occurrence of an unexpected loading has not been accounted for

Figure 10: Initially trained neural network for loading and unloading is not adequate

Figure 11: Neural network trained with the additional input variable - loading-unloading switch

Figure 12: $\quad$ Two loading cycles

Figure 13: Comparison between three oedometer curves with similar Atterberg limits and water content 
Table 1: Some empirical formulae for $C_{c}[6]$

\begin{tabular}{ll}
\hline Equation & Region of applicability \\
\hline$C_{c, 1}=0.007\left(w_{L}-7\right)$ & Remolded clays \\
$C_{c, 2}=1.15\left(e_{0}-0.35\right)$ & All clays \\
$C_{c, 3}=0.30\left(e_{0}-0.27\right)$ & Inorganic, cohesive soil, silt \\
$C_{c, 4}=0.0115 w_{0}$ & Organic soils-meadow mats, peats \\
$C_{c, 5}=0.75\left(e_{0}-0.5\right)$ & Soils of very low plasticity \\
$C_{c, 6}=\left(0.156 e_{0}+0.0107\right)\left(1+e_{0}\right)$ & All clays \\
\hline
\end{tabular}


Table 2: Some numerical data about soil samples composing database

\begin{tabular}{lccc}
\hline Parameter & min. & max. & average \\
\hline Initial void ratio $e_{0}$ & 0.42 & 3.21 & 1.8 \\
Initial water & 15.7 & 119.3 & 39.6 \\
content $w_{0}(\%)$ & & & \\
Liquid limit $w_{L}(\%)$ & 23.1 & 133.1 & 51.6 \\
Plastic limit $w_{P}(\%)$ & 15.0 & 53.4 & 26.6 \\
Plasticity index $I_{P}(\%)$ & 2.9 & 90.6 & 25.0 \\
Consistency index $I_{c}(\%)$ & -2.97 & 2.3 & 0.50 \\
Unit weight $\gamma\left(\mathrm{kN} / \mathrm{m}^{3}\right)$ & 12.3 & 22.2 & 18.3 \\
Depth $z(\mathrm{~m})$ & 0.4 & 41.4 & 9.1 \\
Overconsolidation & 8 & 702 & 92 \\
pressure $\sigma_{P}(\mathrm{kPa})$ & & & \\
Maximum applied stress & 80 & 2000 & \\
during test $\sigma_{v \max }^{\prime}(\mathrm{kPa})$ & & & \\
\hline
\end{tabular}


Table 3: Some data on attained accuracy of oedometer curve, compression index $C_{c}$ and expansion index $C_{e}$ approximations

\begin{tabular}{lccccc}
\hline & $\mathbf{A}$ & $\mathbf{B}$ & $\mathbf{C}$ & $\mathbf{D}$ & $\mathbf{E}$ \\
\hline$\Delta e_{1 \max }(\%)$ & 22.9 & 18.4 & 49.8 & 23.6 & 21.1 \\
$\Delta \bar{e}_{1}(\%)$ & 3.4 & 3.2 & 13.9 & 4.4 & 4.0 \\
$\Delta \tilde{e}_{1}(\%)$ & 2.8 & 2.3 & 12.8 & 3.3 & 3.2 \\
\hline$\Delta e_{2 \max }(\%)$ & 9.1 & 9.3 & 30.4 & 9.2 & 9.1 \\
$\Delta \bar{e}_{2}(\%)$ & 4.1 & 3.2 & 14.0 & 4.3 & 4.0 \\
$\Delta \tilde{e}_{2}(\%)$ & 3.8 & 2.3 & 13.2 & 3.7 & 3.7 \\
\hline$\Delta C_{c \max }(\%)$ & 75.1 & - & 101 & 59.4 & 49.2 \\
$\Delta \bar{C}_{c}(\%)$ & 25.9 & - & 50.6 & 22.0 & 21.1 \\
$\Delta \tilde{C}_{c}(\%)$ & 20.1 & - & 49.5 & 20.8 & 13.6 \\
\hline$\Delta C_{e \max }(\%)$ & - & 71.8 & 41.4 & 60.0 & 70.2 \\
$\Delta \bar{C}_{e}(\%)$ & - & 14.7 & 12.7 & 18.6 & 16.2 \\
$\Delta \tilde{C}_{e}(\%)$ & - & 8.0 & 8.2 & 13.8 & 12.1 \\
\hline
\end{tabular}


Table 4: Comparison between the neural network estimates and some empirical formulae

\begin{tabular}{ccccccc}
\hline \multicolumn{7}{c}{ Mean normalised errors } \\
\hline$C_{c, A N N}$ & $C_{c, 1}$ & $C_{c, 2}$ & $C_{c, 3}$ & $C_{c, 4}$ & $C_{c, 5}$ & $C_{c, 6}$ \\
0.2104 & 0.7835 & 2.9362 & 0.2556 & 1.5212 & 0.7562 & 0.9307 \\
\hline \multicolumn{7}{c}{ Coefficient of correlation } \\
\hline$C_{c, A N N}$ & $C_{c, 1}$ & $C_{c, 2}$ & $C_{c, 3}$ & $C_{c, 4}$ & $C_{c, 5}$ & $C_{c, 6}$ \\
0.9508 & 0.7404 & 0.9283 & 0.9283 & 0.8667 & 0.9283 & 0.9342 \\
\hline
\end{tabular}


a)

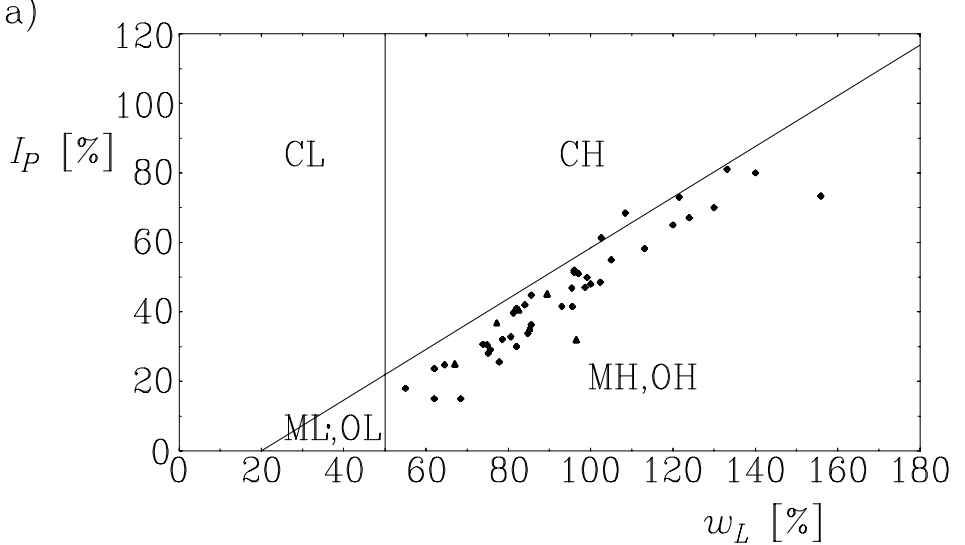

b)

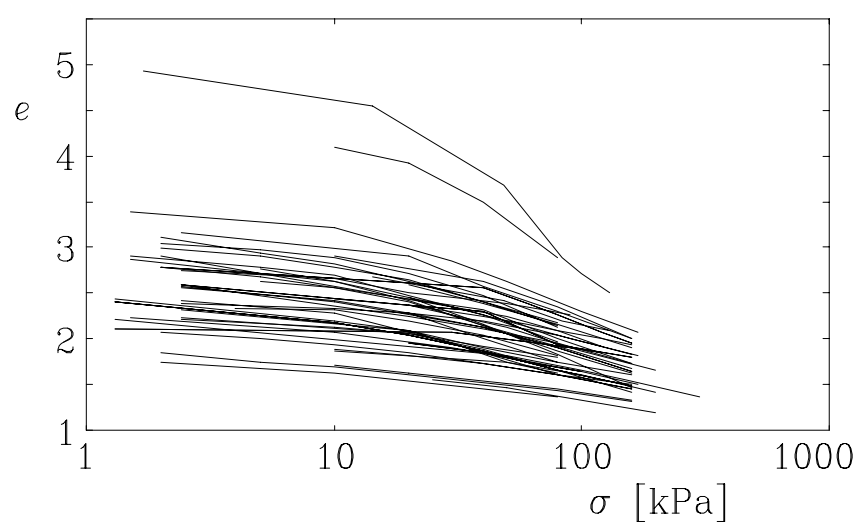

Figure 1 


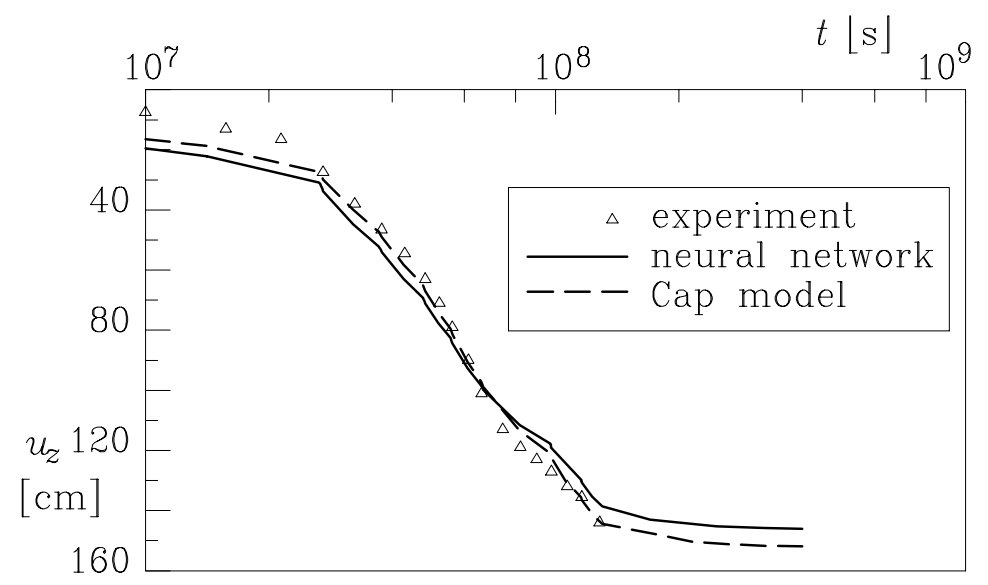

Figure 2 


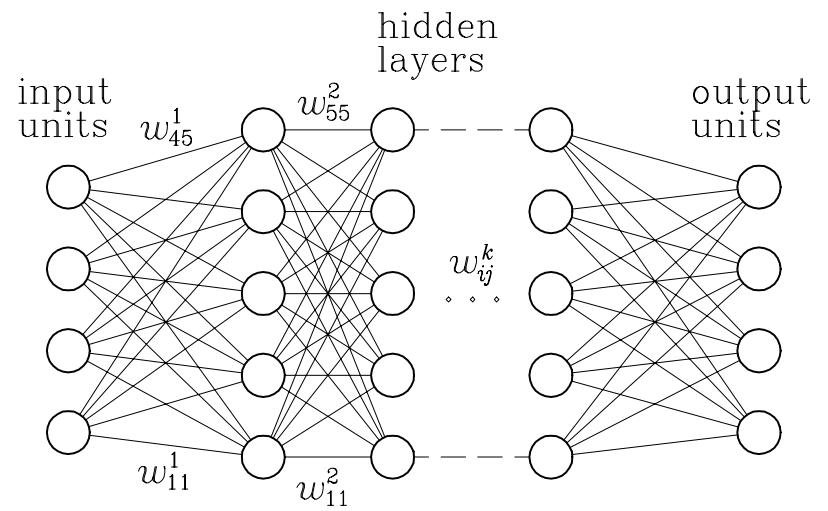

$\begin{array}{llllll}\text { layer } & 0 & 1 & 2 & n_{l}-1 & n_{l}\end{array}$

number 


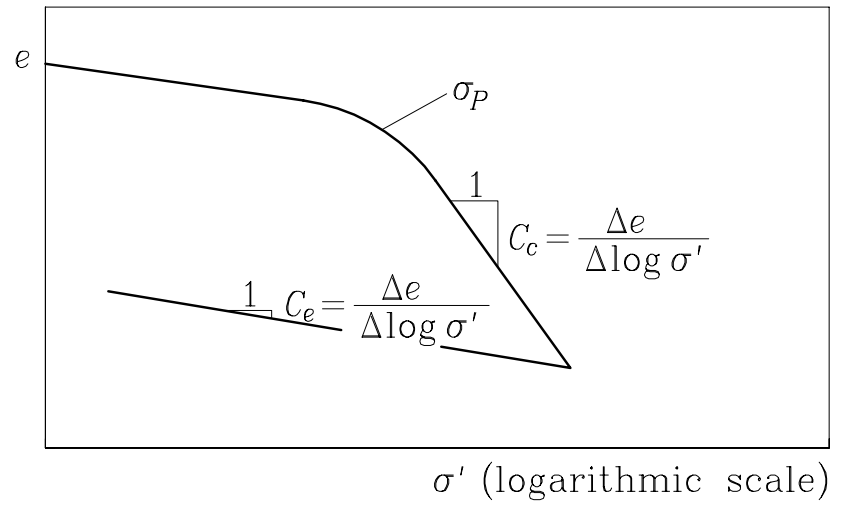

Figure 4 
a)

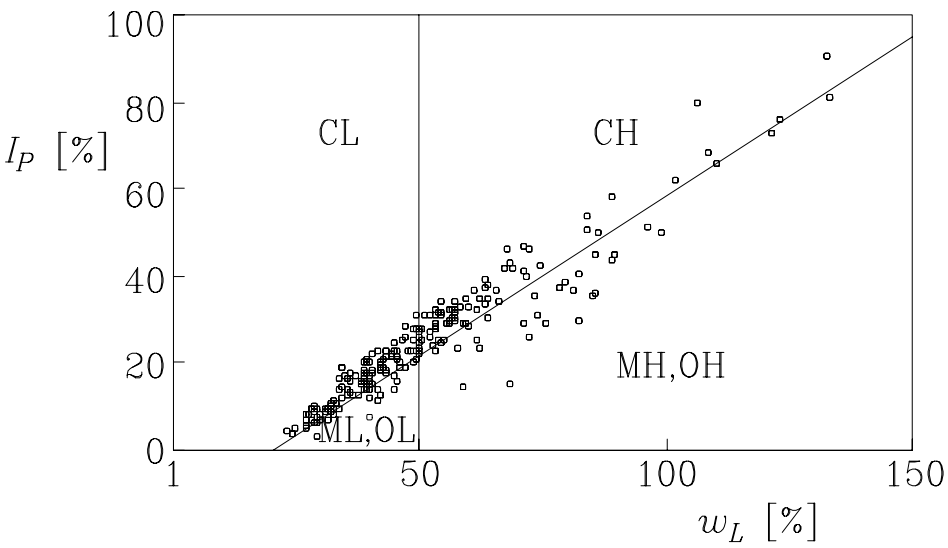

b)

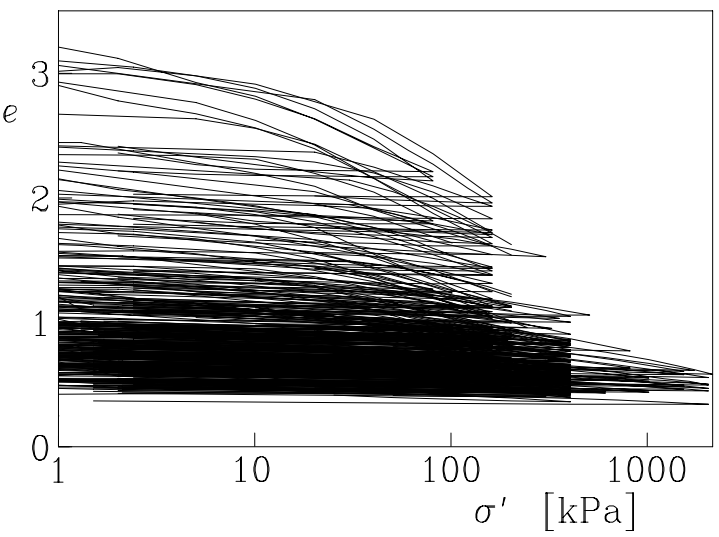




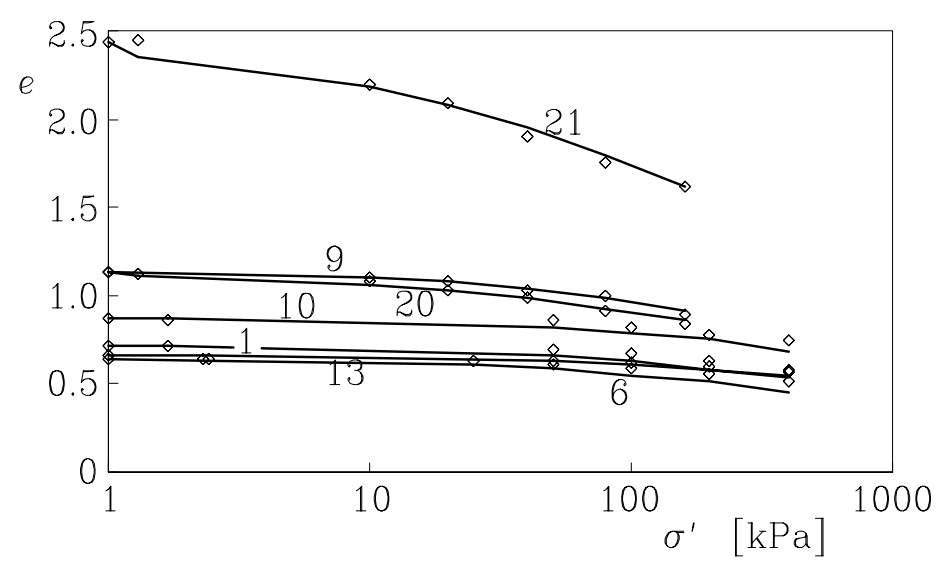

Figure 6 


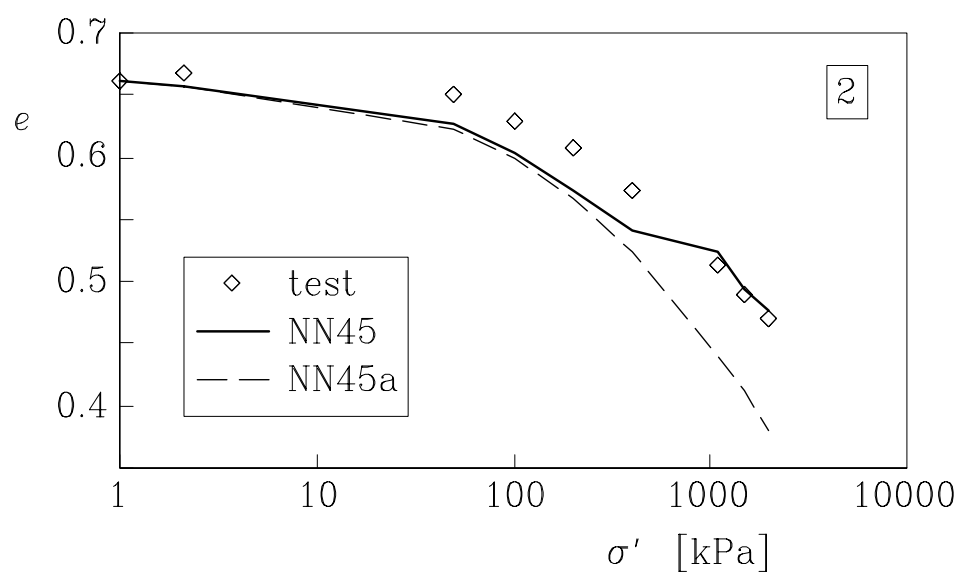

Figure 7 


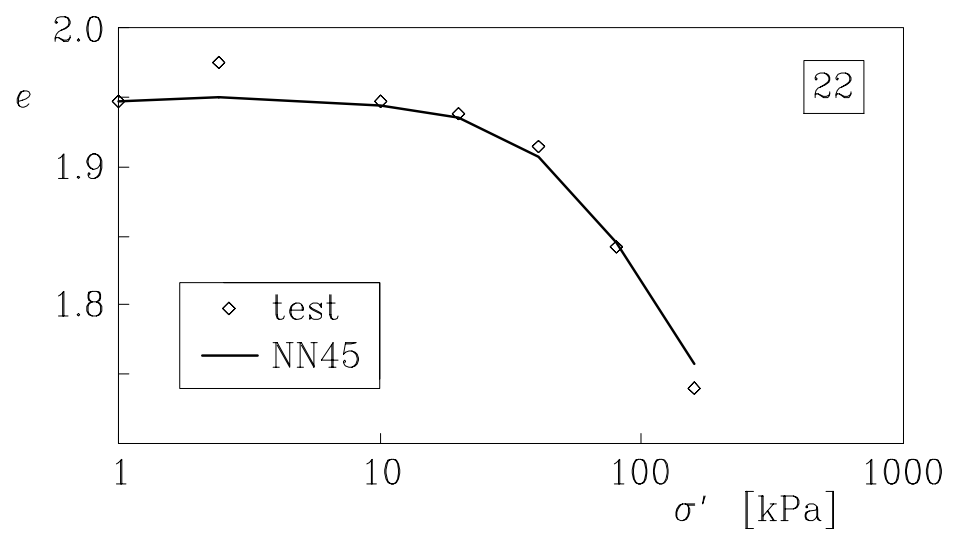

Figure 8 


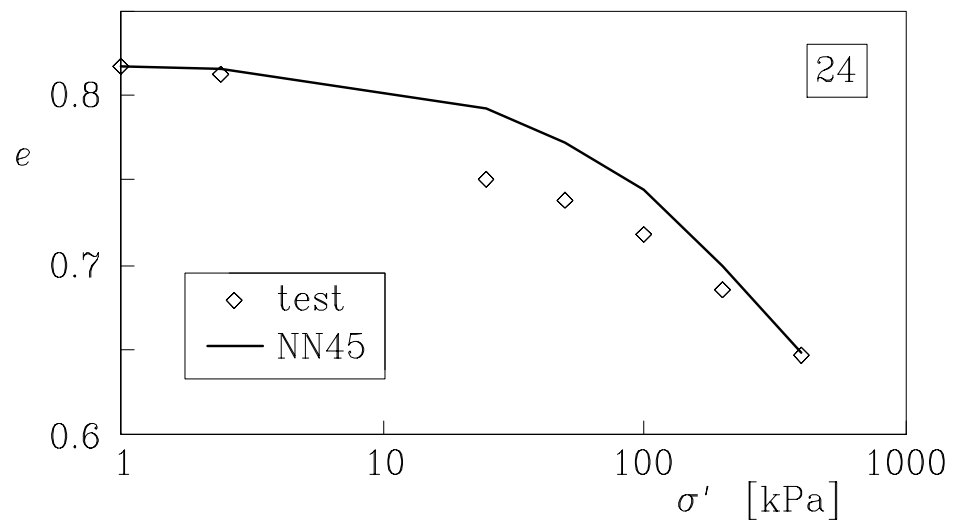

Figure 9 


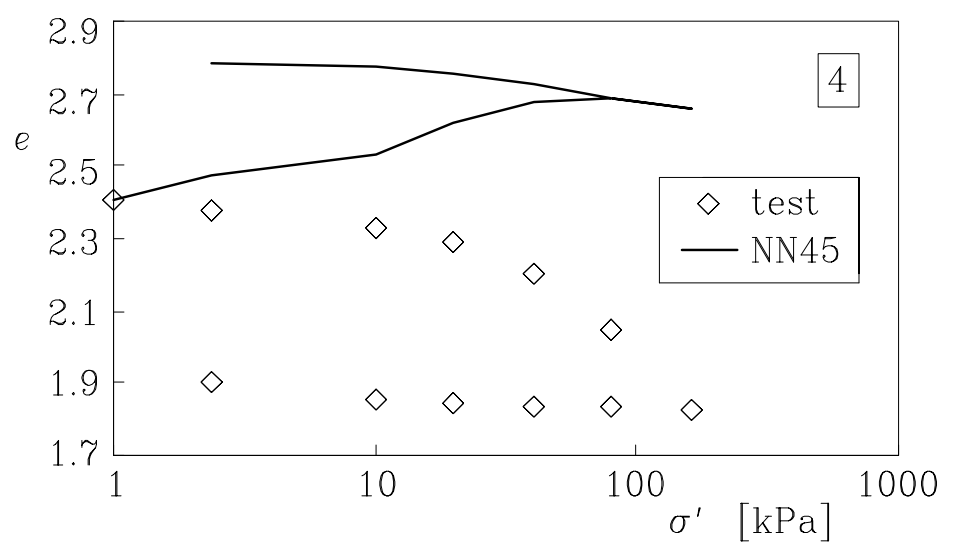

Figure 10 

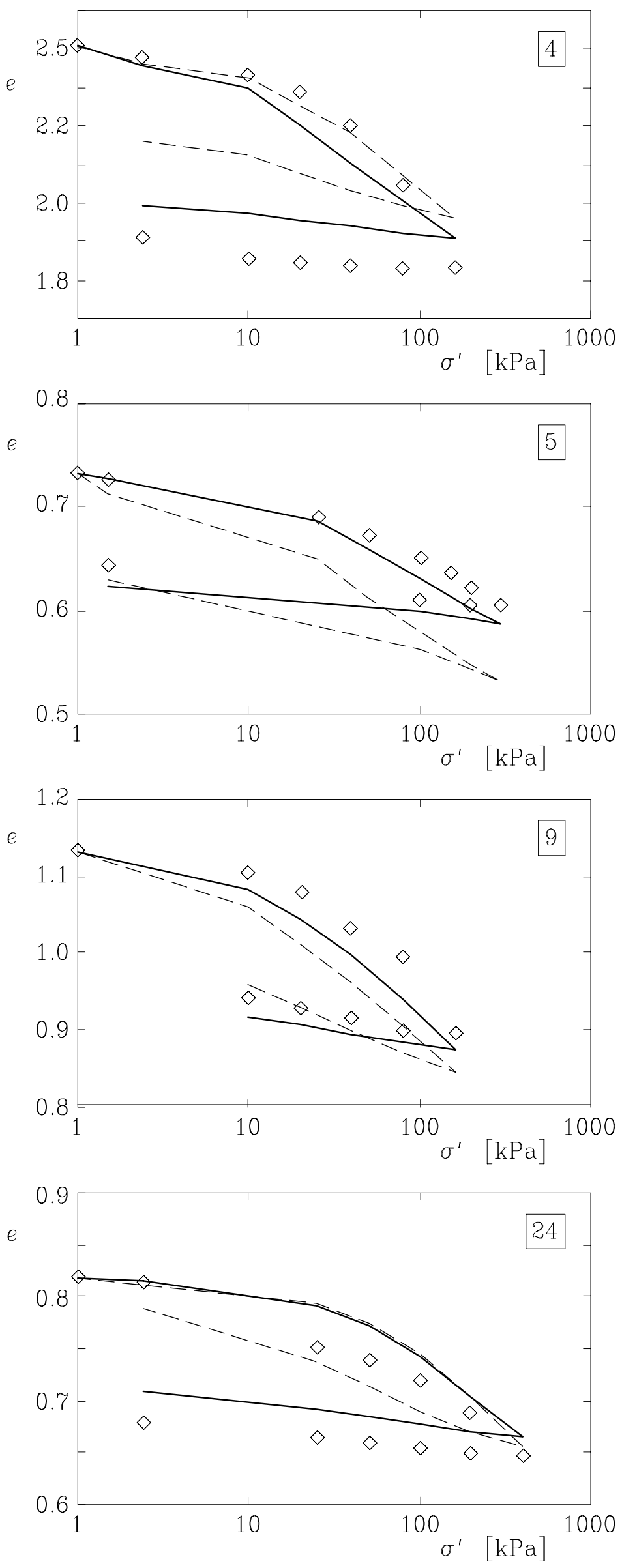

Figure 11 


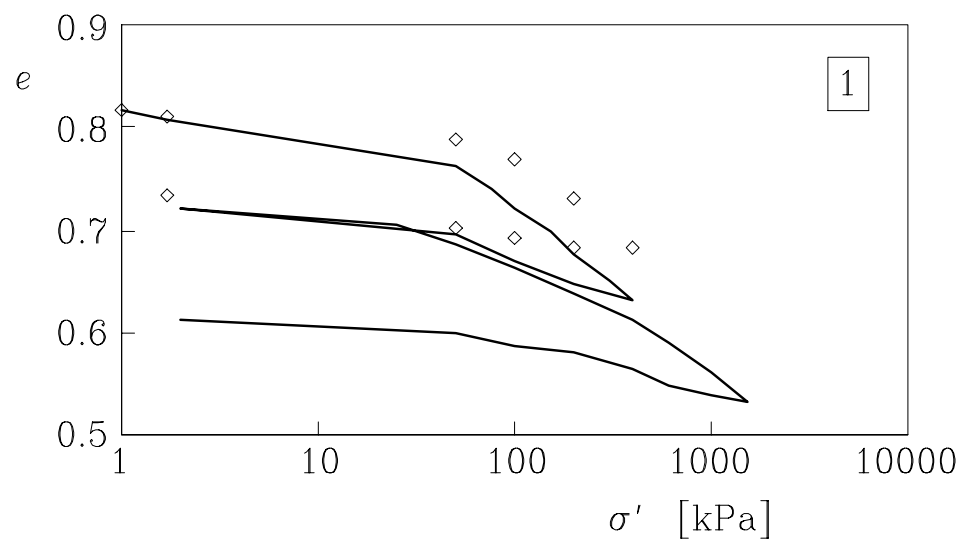

Figure 12 


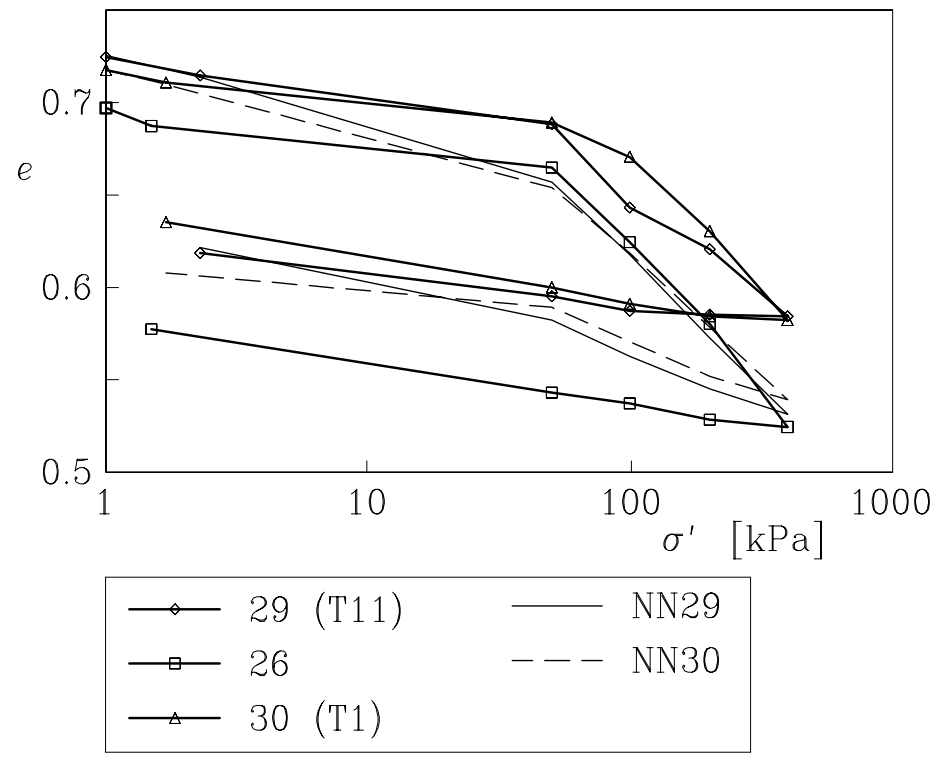

Figure 13 
Suggested abbreviated title: Modelling soil behaviour by neural networks 